\title{
Increased Anticholinergic Challenge-Induced Memory Impairment Associated with the APOE- 84 Allele in the Elderly: A Controlled Pilot Study
}

\author{
Nunzio Pomara*,1,2,4, Lisa M Willoughby', Keith Wesnes ${ }^{3}$ and John J Sidtis ${ }^{2}$ \\ 'Geriatric Psychiatry Program, Nathan Kline Institute for Psychiatric Research, Orangeburg, NY, USA; ${ }^{2}$ Department of Psychiatry, New York \\ University School of Medicine, New York, NY, USA; ${ }^{3}$ Cognitive Treatment Research Ltd., Reading, UK
}

\begin{abstract}
The degree to which elderly adults experience cognitive impairments from centrally acting anticholinergic drugs is variable, but the cause of this variability is unknown. The present study examined the $\varepsilon 4$ allele as a possible modulator of the effects of trihexyphenidyl hydrochloride (Artane ${ }^{\mathrm{TM}}$ ), an anticholinergic drug, on memory functioning. Of the 24 cognitively intact, elderly participants (age range $62-$ 76), 12 who possessed the $\varepsilon 4$ allele, participated in a double-blind, randomized, placebo-controlled, crossover, three-way study. All participants were tested after receiving a single oral dose of trihexyphenidyl ( I or $2 \mathrm{mg}$ ) or placebo, with a 7-day washout period between sessions. Memory and psychomotor tests were administered at baseline, and at I, 2.5, and $5 \mathrm{~h}$ post-treatment. Results showed that participants with the $\varepsilon 4$ allele demonstrated significant impairments in delayed recall after both I and 2 mg doses of trihexyphenidyl while the non- $\varepsilon 4$ group did not. Additionally, while acute administration of the $2 \mathrm{mg}$ dose significantly impaired total recall in both $\varepsilon 4$ and non- $\varepsilon 4$ carriers, the $\varepsilon 4$ carriers showed a more persistent impairment. These findings held when participants with the $\varepsilon 2$ allele were excluded from the analyses. The $\varepsilon 4$ groups did not differ with respect to psychomotor performance or plasma drug levels. These results provide evidence suggesting that the $\varepsilon 4$ allele plays a significant role in increasing cognitive sensitivity to trihexyphenidyl and that a temporal component of memory consolidation may be especially vulnerable. A larger study is warranted to confirm these preliminary findings.
\end{abstract}

Neuropsychopharmacology (2004) 29, 403-409, advance online publication, 17 September 2003; doi:10.1038/sj.npp. I 300305

Keywords: APOE polymorphisms; anticholinergic hypersensitivity; muscarinic antagonists; elderly; memory; neuronal plasticity

\section{INTRODUCTION}

Medications with central anticholinergic effects are widely prescribed in the elderly and are a common cause of adverse treatment reactions (Agostini et al, 2001). One of the potentially debilitating side effects of these treatments is impaired cognitive functioning. In the case of a centrally acting muscarinic antagonist, trihexyphenidyl hydrochloride (Artane ${ }^{\mathrm{TM}}$ ), several investigators have demonstrated memory deficits in healthy elderly volunteers in response to acute doses (Guthrie et al, 2000; Nakra et al, 1992). For example, Nakra and co-workers reported that the administration of a single $2 \mathrm{mg}$ oral dose of trihexyphenidyl was associated with significant impairments in immediate and delayed recall in cognitively intact, elderly volunteers.

\footnotetext{
*Correspondence: Dr N Pomara, Geriatric Psychiatry Program, Nathan S Kline Institute, 140 Old Orangeburg Rd. Bldg. 35, Orangeburg, NY I0962, USA, Tel: + I 845398 5579, Fax: + I 845398 5575,

E-mail: pomara@nki.rfmh.org

${ }^{4}$ This study was supported in part by Grant ROI MH056994

Received 13 May 2003; revised 31 July 2003; accepted 06 August 2003 Online publication: 8 August 2003 at http://www.acnp.org/citations/ NPP08080303209/default.pdf
}

Another muscarinic antagonist, scopolamine, has also been described as inducing cognitive deficits in elderly volunteers (Flicker et al, 1992; Molchan et al, 1992; Ray et al, 1992; Zemishlany and Thorne, 1991), but with some intersubject variability unrelated to pharmacokinetic factors, such as plasma drug level (Tariot et al, 1996). The basis for the intersubject variability in response to anticholinergic treatment is not known, but could reflect individual differences in central cholinergic function or reserve.

A viable individual difference factor associated with central cholinergic function is the APOE- $\varepsilon 4$ allele, which is considered a major genetic risk factor for sporadic and lateonset familial Alzheimer's disease (AD) (Saunders et al, 1993). Post-mortem brain tissue samples from AD patients who are 84 carriers have shown greater reductions in choline acetyltranferase (ChAT) activity, a cholinergic marker enzyme, in the hippocampus (Poirier, 1994; Allen et al, 1997), temporal cortex and nucleus basalis of Meynert (NBM) (Arendt et al, 1997), and the frontal cortex (Soininen et al, 1995). Other reports have also pointed to greater reductions in ChAT activity in $\mathrm{AD}$ patients homozygous for the $\varepsilon 4$ allele $(\varepsilon 4 / \varepsilon 4)$ in the hippocampus (Poirier, 1994) and the frontal cortex (Soininen et al, 1995) than AD patients 
who were heterozygous (ie $\varepsilon 4 / \varepsilon 3$ or $\varepsilon 4 / \varepsilon 2$ ). Further studies have provided support linking the greater cholinergic abnormalities associated with the $\varepsilon 4$ allele to reduced cholinergic repair mechanisms and plasticity. For instance, Poirier et al (1995) showed that while AD patients with and without the 84 allele had a comparable loss of cholinergic neurons in the basal forebrain, 84 carriers had greater reductions in ChAT activity in terminal projection areas (ie hippocampus, temporal cortex) than noncarriers. Furthermore, despite a $60 \%$ loss of AchE-positive neurons in the basal forebrain, ChAT activity in the hippocampus and cortex of $\varepsilon 4$ noncarrier AD subjects was relatively similar to that of $\varepsilon 4$ noncarrier controls. Similar results were reported by Arendt et al (1997). In a post-mortem study of nondemented subjects, Allen et al (1997) showed significantly greater reductions in ChAT activity in the temporal cortex of $\varepsilon 4$ carriers compared to $\varepsilon 4$ noncarriers. To date, the relevance of these post-mortem findings to clinical populations has been limited to studies that have examined the relationship between the $\varepsilon 4$ allele and therapeutic response to cholinergic agonists in $\mathrm{AD}$ patients. It may be that $\varepsilon 4$ is associated with increased sensitivity to anticholinergic drug-induced cognitive toxicity, but this has not been studied directly.

These considerations provided the rationale for this controlled study to investigate the role of the $\varepsilon 4$ allele as a factor associated with the intersubject variability in cognitive deficits induced from treatment of trihexyphenidyl, a muscarinic anticholinergic agent.

\section{METHODS}

\section{Participants}

In all, $12 \varepsilon 4$-positive and $12 \varepsilon 4$-negative, cognitively intact, elderly adults were recruited from a pre-existing subject pool of 76 adults who previously completed a study examining the relationship between the APOE- 84 genotype and the effects of lorazepam on cognitive performance. All of the participants were community-dwelling individuals who were initially recruited through newspaper ads and flyers posted in community centers, libraries, and other public places. The $\varepsilon 4$ group consisted of two $\varepsilon 4 / \varepsilon 2$ (two male) and $10 \varepsilon 4 / \varepsilon 3$ (four male and six female) participants. The 84 -negative group consisted of five $83 / \varepsilon 2$ (three male and two female) and seven $83 / \varepsilon 3$ (two male and five female) participants. The groups were matched for age and education and each participant was paid $\$ 140$ at the end of the study. The study was approved by the Institutional Review Board at the Nathan S Kline Institute for Psychiatric Research and all participants provided written consent and confidentiality was strictly enforced. Neither study participants nor staff involved in the psychometric and safety assessments had access to the genetic data.

Participants were free of significant neurological and medical illnesses as determined by history, physical examination, routine laboratory tests, and neuropsychological examination. Main demographic characteristics and psychometric performance at screening are listed in Table 1. Individuals did not take medications known to affect cognitive functioning, such as neuroleptics and antidepressants, at least 2 weeks before beginning the study and had a
Table I Participant Characteristics Recorded at Screening by APOE- $\varepsilon 4$ Allele Status

\begin{tabular}{|c|c|c|}
\hline Characteristics & APOE- $\varepsilon 4, n=12$ & No APOE- $\varepsilon 4, n=12$ \\
\hline \multicolumn{3}{|l|}{ Age (years) } \\
\hline Median (range) & $67(62-76)$ & $67(62-72)$ \\
\hline Mean \pm SD & $67.33 \pm 4.58$ & $66.92 \pm 3.29$ \\
\hline \multicolumn{3}{|l|}{ Weight (lbs) } \\
\hline Median (range) & $175(|35-24|)$ & $165(135-190)$ \\
\hline Mean \pm SD & $181.25 \pm 35.70$ & $165.25 \pm 13.94$ \\
\hline \multicolumn{3}{|l|}{ Education (years) } \\
\hline Median (range) & $15(9-18)$ & $16.50(\mid 4-22)$ \\
\hline Mean \pm SD & $14.50 \pm 2.94$ & $17.08 \pm 3.14$ \\
\hline \multicolumn{3}{|c|}{ Hamilton Anxiety Scale } \\
\hline Median (range) & I (0-6) & I (0-4) \\
\hline Mean $\pm S D$ & $2.18 \pm 2.32$ & $1.50 \pm 1.62$ \\
\hline \multicolumn{3}{|c|}{ Hamilton Depression Scale } \\
\hline Median (range) & $0(0-6)$ & $0(0)$ \\
\hline Mean $\pm S D$ & $0.82 \pm 1.94$ & $0.00 \pm 0$ \\
\hline \multicolumn{3}{|c|}{ Mini Mental Status Exam } \\
\hline Median (range) & $29.50(28-30)$ & $29.50(29-30)$ \\
\hline Mean $\pm S D$ & $29.33 \pm 0.78$ & $29.50 \pm 0.53$ \\
\hline \multicolumn{3}{|l|}{ WAIS-R $R^{\text {a }}$ vocabulary } \\
\hline Median (range) & $12(5-18)$ & $12.50(7-19)$ \\
\hline Mean \pm SD & $12.00 \pm 3.59$ & $12.50 \pm 3.06$ \\
\hline \multicolumn{3}{|c|}{ WMS-R ${ }^{\mathrm{a}}$ General Memory Index } \\
\hline Median (range) & $103.50(64-132)$ & $\mid 19.50(9|-| 60)$ \\
\hline Mean \pm SD & $102.17 \pm 22.04$ & $117.83 \pm 18.41$ \\
\hline \multicolumn{3}{|c|}{ Family history of AD } \\
\hline Yes/No & $6 / 6$ & $7 / 5$ \\
\hline \multicolumn{3}{|l|}{ Sex } \\
\hline Male/Female & $6 / 6$ & $5 / 7$ \\
\hline
\end{tabular}

aWAIS-R, Wechsler Adult Intelligence Scale-Revised; WMS-R, Wechsler Memory Scale_-Revised.

negative urine toxicology screen. No participant met DSMIV criteria for a psychiatric disorder and all were free of significant anxiety or depressive symptoms as determined by the Hamilton Rating Scales for Anxiety and Depression. None of the individuals had a history of psychiatric illness or treatment. Finally, all participants obtained average or better scores than gender and age-adjusted values on the Wechsler Memory Scale - Revised General Memory Index, Wechsler Adult Intelligence Scale-Revised (WAIS-R) Vocabulary subtest, and minimental state exam. MannWhitney $U$-test and $\chi^{2}$ tests indicated no significant differences $(p>0.05)$ between $\varepsilon 4$ and non- $\varepsilon 4$ groups on 
any of the demographic variables or cognitive screening measures reported in Table 1.

\section{Design and Procedures}

The study was carried out according to a double-blind, randomized, placebo-controlled, three-way, crossover design. Following completion of the screening evaluation, individuals participated in three acute sessions, 1 week apart, during which they were administered oral doses of trihexyphenidyl $\left(\right.$ Artane $\left.^{\mathrm{TM}}\right)$, (1 or $2 \mathrm{mg}$ ) or placebo. Study medications and identical placebo capsules were prepared by the hospital pharmacy. Treatment sequences were randomly assigned and balanced. Each test session began at approximately 0900 under nonfasting conditions and after obtaining a brief health history and vital signs. A battery of psychometric tests was administered just prior to (baseline) and 1, 2.5, and $5 \mathrm{~h}$ after treatment administration. The psychometric battery included the Buschke Selective Reminding Task (BSRT) total recall subtest, WAIS-R forward and reverse digit span tasks, the Purdue Pegboard test, and the BSRT delayed recall subtest.

\section{APOE Genotyping}

APOE genotyping was performed at the Northwest Research Laboratories at the University of Washington, using the restriction enzyme isoform genotyping method described by Hixson and Vernier (1990).

\section{Psychometric: Testing}

The BSRT (Buschke, 1973, 1974) was used to evaluate memory functioning during the sessions. The BSRT assesses a wide range of memory functioning and for the purposes of this report, data from the total and delayed recall components were summarized. Total recall scores reflected the sum of words correctly recalled by participants immediately after list presentation and delayed recall scores reflected the total number of words recalled after $15 \mathrm{~min}$ had passed since the end of the BSRT final recall phase. Full procedural details and the construction of the alternate forms used in the present study are described elsewhere (Pomara et al, 1998). In order to normalize performance across the different versions of the BSRT, mean values for each version were computed from the placebo conditions. The highest mean value across versions was used as the numerator and the mean scores for each of the versions were used as denominators for the normalization. These simple ratio normalization values were then applied to each version across treatment conditions (Arndt et al, 1996). The Purdue pegboard task was used to measure psychomotor functioning (Tiffin, 1968). The task requires participants to place as many pegs as possible into a holed square palate for $30 \mathrm{~s}$. Participants completed three pegboard trials that required the sole use of a dominant hand, nondominant hand, and both hands. The number of correctly inserted pegs were counted and recorded. Finally, a WAIS-R digit span task was administered at each time point to prevent rehearsal of BSRT items between the total and delayed recall tasks.

\section{Plasma Drug Levels}

Blood samples were collected before each psychometric assessment for quantitation of trihexyphenidyl plasma concentrations. Drug levels were assayed via gas chromatography using a nitrogen-specific detector.

\section{Statistical Analyses}

In these analyses, we defined treatment effects as the difference between performance following the administration of 1 or $2 \mathrm{mg}$ trihexyphenidyl and performance with placebo at a particular test time point. Separate mixedmodel factorial repeated measures analyses of variance (ANOVAs) were performed on each of the outcome measures (post-treatment performance minus baseline). Separate ANOVAs were used to compare a particular trihexyphenidyl level ( 1 or $2 \mathrm{mg}$ ) to placebo, with time as a repeated variable $(1,2.5$, and $5 \mathrm{~h})$ and APOE allele status $(\varepsilon 4$ and non- $\varepsilon 4)$ as a between subjects factor. All paired contrasts were analyzed using $t$-tests and a criterion of 0.025 was applied to these analyses. For the purposes of this report, the measures that were analyzed using the full model ANOVA included the BSRT total and delayed recall measures and the single- and two-hand components of the Purdue Pegboard task.

One non- $\varepsilon 4$ subject had to leave a placebo testing prior to the $5 \mathrm{~h}$ evaluation. The missing data points were replaced with mean values for the non- $\varepsilon 4$ group $5 \mathrm{~h}$ placebo condition. Another non- $\varepsilon 4$ subject had an unrelated nondominant hand injury that affected motor performance during all conditions. That subject's missing data for the nondominant hand and both-hand pegboard trials were replaced with condition-appropriate mean scores from the non- $\varepsilon 4$ group.

\section{RESULTS}

\section{Total Recall}

BSRT scores for total recall are summarized in Table 2. A main effect of treatment type indicated that compared to placebo, the $2 \mathrm{mg}$ dose of trihexyphenidyl significantly reduced total recall from baseline $(\mathrm{F}(1,22)=9.17$, $p=0.006)$. The effect was significant at $1(p=0.004)$ and $2.5 \mathrm{~h}(p=0.004)$ but not at $5 \mathrm{~h}$. The effect of the $1 \mathrm{mg}$ dose did not reach statistical significance $(F \quad(1,22)=0.69$, $p=0.415)$. Overall, the $\varepsilon 4$ allele status did not significantly interact with treatment type to affect total recall when placebo was compared with the $1 \mathrm{mg}$ dose $(\mathrm{F}(1,22)=0.001$, $p=0.982)$ or the $2 \mathrm{mg}$ dose $(\mathrm{F}(1,22)=0.53, p=0.473)$. However, memory impairment improved significantly from 2.5 to $5 \mathrm{~h}$ in the non- $\varepsilon 4$ group $(p=0.012)$ but not in the $\varepsilon 4$ participants $(p=0.17)$ (Figure 1).

\section{Delayed Recall}

Delayed recall scores from the BSRT are listed in Table 2. A comparison of $2 \mathrm{mg}$ trihexyphenidyl and placebo revealed a significant main effect of treatment type $(F(1,22)=8.20$, $p=0.009$ ), with $2 \mathrm{mg}$ trihexyphenidyl leading to a greater reduction in delayed recall from baseline when compared to 
Table 2 Means and SDs of the BSRT Normalized Values

\begin{tabular}{|c|c|c|c|c|c|c|}
\hline \multirow[b]{2}{*}{ Group } & \multicolumn{3}{|c|}{ Total recall } & \multicolumn{3}{|c|}{ Delayed recall } \\
\hline & Placebo & I mg & $2 \mathrm{mg}$ & Placebo & I mg & $2 \mathrm{mg}$ \\
\hline $\mathrm{Oh}$ & $60.48 \pm 16.02$ & $60.72 \pm 17.08$ & $63.16 \pm 18.21$ & $7.43 \pm 3.56$ & $7.27 \pm 4.42$ & $9.01 \pm 3.32$ \\
\hline $\mathrm{Ih}$ & $53.90 \pm 17.82$ & $53.76 \pm 18.40$ & $47.71 \pm 14.85$ & $6.54 \pm 5.61$ & $6.25 \pm 4.92$ & $5.53 \pm 3.42$ \\
\hline \multicolumn{7}{|l|}{ Non- $\varepsilon 4$} \\
\hline $\mathrm{Oh}$ & $69.12 \pm 12.07$ & $66.31 \pm 13.10$ & $65.44 \pm 12.22$ & $8.81 \pm 3.23$ & $8.41 \pm 2.59$ & $7.51 \pm 2.62$ \\
\hline $\mathrm{Ih}$ & $61.87 \pm 14.59$ & $58.87 \pm 12.40$ & $54.31 \pm 15.34$ & $7.78 \pm 5.39$ & $5.73 \pm 3.65$ & $4.76 \pm 4.72$ \\
\hline $2.5 \mathrm{~h}$ & $64.55 \pm 18.18$ & $55.28 \pm 9.10$ & $49.05 \pm 15.06$ & $8.39 \pm 4.29$ & $7.21 \pm 3.20$ & $6.23 \pm 3.85$ \\
\hline
\end{tabular}

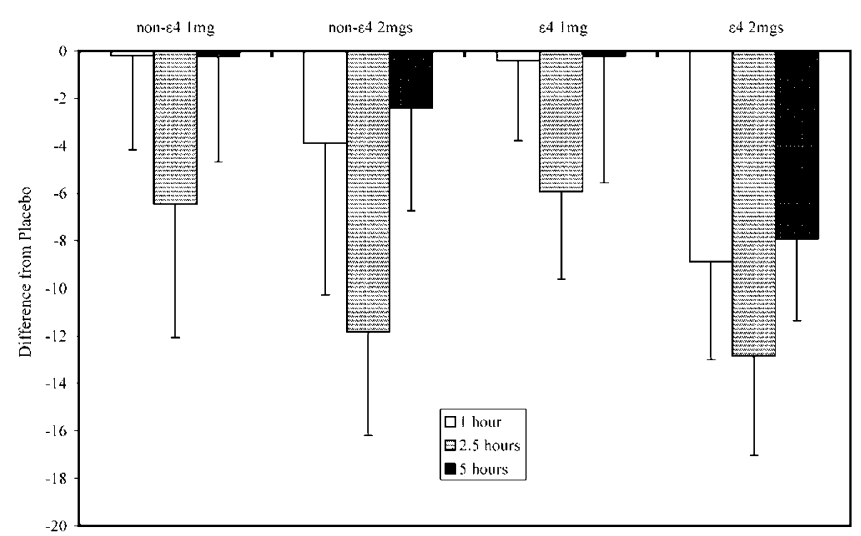

Figure I Difference from placebo total recall change from baseline scores following administration of $\mathrm{I}$ and $2 \mathrm{mg}$ trihexyphenidyl (error bars $=\mathrm{SE})$.

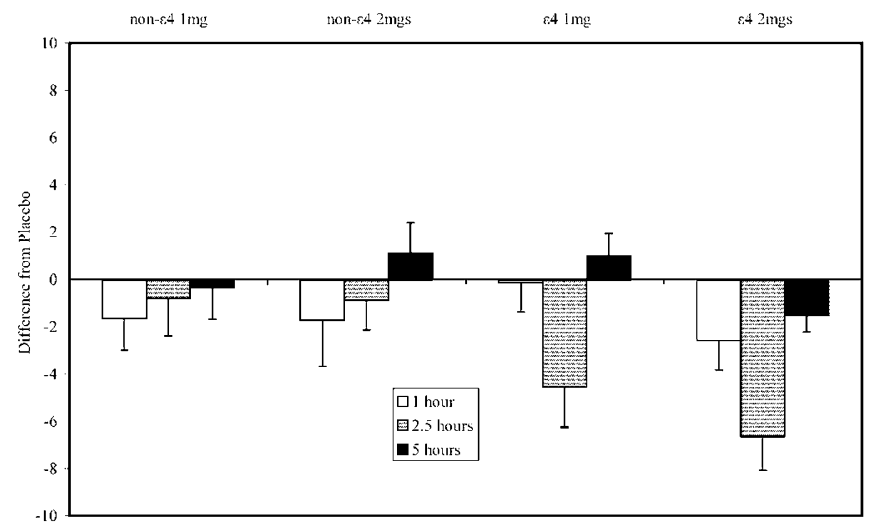

Figure 2 Difference from placebo delayed recall change from baseline scores following administration of $\mathrm{I}$ and $2 \mathrm{mg}$ trihexyphenidyl (error bars $=\mathrm{SE})$.

placebo. In addition, treatment type significantly interacted with APOE allele status (F $(1,22)=4.71, p=0.041)$ and trend analyses revealed a significant quadratic three-way trend between allele status, treatment type, and time (F $(1,22)=8.20, p=0.009)$, indicating that treatment effects differed between groups as a function of test times (Figure 2). Specifically, $2 \mathrm{mg}$ trihexyphenidyl reduced delayed recall scores from baseline relative to placebo only in the group with the $\varepsilon 4$ allele at $2.5 \mathrm{~h}(p=0.001)$ and the difference in the amount of reduction at this time was significantly greater in the group with the 84 allele than the group without the $\varepsilon 4$ allele $(p=0.01)$. The adverse effects of $2 \mathrm{mg}$ trihexyphenidyl on delayed recall observed in the $\varepsilon 4$ group improved significantly between 2.5 and $5 \mathrm{~h}$ $(p=0.020)$.

At the lower dose of trihexyphenidyl, a significant threeway interaction between the $\varepsilon 4$ allele status, treatment type, and time was found when reductions in delayed recall from baseline under $1 \mathrm{mg}$ trihexyphenidyl were compared to placebo $(\mathrm{F}(2,44)=4.44, p=0.017)$ and as with the previous analyses, a significant quadratic trend was found for this interaction $(\mathrm{F}(1,22)=4.71, p=0.039)$. When given $1 \mathrm{mg}$ trihexyphenidyl, the $\varepsilon 4$-positive group exhibited significantly greater reduction from baseline in delayed recall scores at the $2.5 \mathrm{~h}$ test time relative to placebo $(p=0.022)$ and the drug-induced impairment in memory improved by $5 \mathrm{~h}(p=0.014)$.

A subset of individuals who were genotyped as $\varepsilon 3 / \varepsilon 3$ $(n=7)$ and $\varepsilon 4 / \varepsilon 3 \quad(n=10)$ were selected for secondary analyses to determine whether observed differences in total and delayed recall associated with the $\varepsilon 4$ allele status could be attributed to the higher number of individuals in the non- $\varepsilon 4$ group who possessed the $\varepsilon 2$ allele. Eliminating the individuals with the $\varepsilon 2$ allele in both the groups did not alter the pattern of results observed in the full sample of subjects (Table 3).

\section{Purdue Pegboard}

The question of whether the $\varepsilon 4$ allele modulated the effect of trihexyphenidyl on psychomotor performance was addressed by an examination of performance on the Purdue Pegboard. As with the memory measures, the posttreatment Purdue Pegboard data for the dominant hand, nondominant hand, and both-hand trials were transformed to change from baseline scores. Repeated measures ANOVAs comparing each drug level to placebo across time 
Table 3 Means and SDs of the BSRT Normalized Values for $\varepsilon 2$-Excluded Subsets

\begin{tabular}{|c|c|c|c|c|c|c|}
\hline \multirow[b]{2}{*}{ Group } & \multicolumn{3}{|c|}{ Total recall } & \multicolumn{3}{|c|}{ Delayed recall } \\
\hline & Placebo & I mg & $2 \mathrm{mg}$ & Placebo & I mg & $2 \mathrm{mg}$ \\
\hline $\mathrm{Oh}$ & $62.17 \pm 16.53$ & $61.42 \pm 18.75$ & $64.19 \pm 19.95$ & $7.82 \pm 3.74$ & $7.09 \pm 4.84$ & $9.26 \pm 3.60$ \\
\hline I h & $55.56 \pm 18.96$ & $54.34 \pm 20.25$ & $48.05 \pm 16.36$ & $6.79 \pm 6.04$ & $6.79 \pm 4.98$ & $5.82 \pm 3.71$ \\
\hline \multicolumn{7}{|l|}{$\varepsilon 3 / \varepsilon 3$} \\
\hline $\mathrm{Oh}$ & $66.39 \pm 9.46$ & $64.92 \pm 13.70$ & $68.49 \pm 12.47$ & $8.56 \pm 2.59$ & $7.96 \pm 2.56$ & $7.85 \pm 2.25$ \\
\hline I h & $61.73 \pm 9.42$ & $58.49 \pm 13.56$ & $48.83 \pm 4.85$ & $8.22 \pm 4.25$ & $6.34 \pm 2.88$ & $3.13 \pm 1.78$ \\
\hline $2.5 \mathrm{~h}$ & $61.78 \pm 11.11$ & $56.00 \pm 10.53$ & $50.11 \pm 10.05$ & $7.71 \pm 1.40$ & $8.43 \pm 3.41$ & $7.04 \pm 2.00$ \\
\hline
\end{tabular}

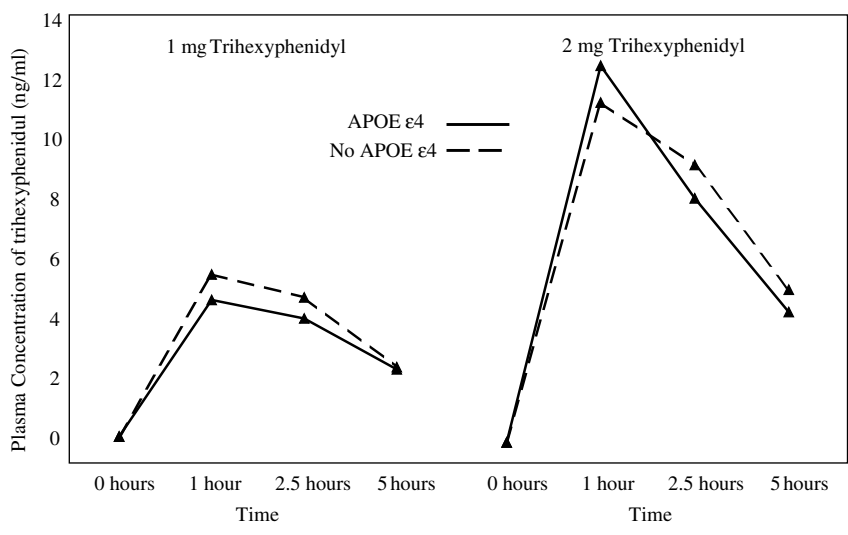

Figure 3 Plasma drug levels of trihexyphenidyl $(\mathrm{ng} / \mathrm{ml})$ at the times following administration.

yielded no significant $\varepsilon 4$ interaction with treatment or time for the dominant hand, nondominant hand, and both-hand Purdue Pegboard trials. In addition, no treatment effects were found when repeated measures ANOVAs were carried out across treatment levels within each time for each of the 84 groups. To conclude, the analyses performed on the Purdue Pegboard measures did not produce any evidence that reactions to trihexyphenidyl during a psychomotor task varied as a function of allele status.

\section{Order Effects}

A repeated measures ANOVA that included treatment order as an additional between subjects variable indicated that treatment order did not simultaneously interact with treatment type, allele status, and time on all outcome measures.

\section{Plasma: Drug Level}

Trihexyphenidyl plasma concentrations at different time points are presented in Figure 3. No significant differences were detected between the $\varepsilon 4$ allele groups.

\section{DISCUSSION}

The results of this study demonstrate that an acute administration of $2 \mathrm{mg}$ of trihexyphenidyl produces significant impairments in total recall in both the $\varepsilon 4$ and the non- $\varepsilon 4$ participants, but this impairment improves significantly by $5 \mathrm{~h}$ in the non- $\varepsilon 4$ participants but not in participants who possess the $\varepsilon 4$ allele. The differences in how these groups respond to trihexyphenidyl are more marked when delayed recall is examined. While there was no significant treatment effect on delayed recall in the non$\varepsilon 4$ group, the $\varepsilon 4$ participants experienced significant deficits on delayed recall following acute administrations of both 1 and $2 \mathrm{mg}$ of trihexyphenidyl. These findings held when participants with the $\varepsilon 2$ allele were excluded from the analyses. In contrast to memory performance, there were no significant 84 group differences in psychomotor performance following trihexyphenidyl treatment. The differences in memory function in the $\varepsilon 4$ groups cannot be accounted for by differences in trihexyphenidyl plasma levels.

In a similar study examining the relationship between allele status and response to a benzodiazepine, we observed that the $\varepsilon 4$ allele was also associated with decreased recovery of memory functions following administration of a single $1.0 \mathrm{mg}$ dose of lorazepam (Pomara et al, in preparation). More specifically, the benzodiazepine effect that differentiated between the $\varepsilon 4$ and the non- $\varepsilon 4$ groups was seen on measures of long-term memory $5 \mathrm{~h}$ after the treatment was administered. Thus, the decreased recovery that we observed in the $\varepsilon 4$ participants following acute administration of two classes of treatments with relatively distinct pharmacological actions is consistent with other findings and suggest that the $\varepsilon 4$ allele is associated with a general vulnerability of the brain to recover from various pharmacological and neurological insults (Alberts et al, 1995; Friedman et al, 1999; Mayeux et al, 1996; Sorbi et al, 1995).

The cause of the increased sensitivity to the adverse effects of trihexyphenidyl in the APOE- 84 carriers is not known. One likely factor affecting variations in sensitivity to anticholinergic agents is the integrity of the central cholinergic system. It has been suggested that cognitive 
responses to an anticholinergic challenge, such as scopolamine, reflect central cholinergic function (Ray et al, 1992; Tariot et al, 1996). The hypersensitivity to scopolamine, which has been demonstrated in elderly participants when compared to younger participants (Flicker et al, 1992; Ray et al, 1992; Zemishlany and Thorne, 1991) and in participants with AD when compared to non-demented elderly participants (Sunderland et al, 1987), is consistent with the well-established age- and AD-related changes in a number of markers, including reductions in the size and number of cholinergic neurons in the NBM (McGeer et al, 1984; Whitehouse et al, 1982). Thus, the increased cognitive toxicity to trihexyphenidyl that we observed in participants with the APOE- $\varepsilon 4$ allele may reflect some form of decreased cholinergic function or reserve in this population. This hypothesis is consistent with a preliminary report in normal elderly and with the body of data derived from post-mortem studies in AD patients, briefly summarized in the introduction, linking the APOE- $\varepsilon 4$ allele to greater reductions in various cholinergic indices in specific brain regions, including the hippocampus and frontal cortex. Another possibility for the increased anticholinergic sensitivity that we observed in individuals with the $\varepsilon 4$-allele is that this group might have included individuals in the earliest stages of $\mathrm{AD}$, who were not necessarily identified by the psychometric battery that was employed in the current study.

The relationship between cognitive toxicity, the role of the $\varepsilon 4$ allele, and cholinergic function is likely not simple. In contrast to earlier findings (Poirier et al, 1995), not all subsequent investigations have found a relationship between APOE genotype and treatment response to cholinesterase inhibitors in AD (Farlow et al, 1999; Raskind et al, 2000). Additionally, not all studies have found a relationship between the $\varepsilon 4$ allele and cholinergic abnormalities in $\mathrm{AD}$ (Corey-Bloom et al, 2000; Svensson et al, 1997) and related animal models (Bronfman et al, 2000). The basis for the conflicting results in human studies is not known but could be due to methodological differences, including the brain region sampled and autopsy time intervals. Another factor is the degree to which the 84 -positive and -negative $\mathrm{AD}$ groups were matched with respect to duration or severity of dementia, variables that could influence cholinergic indices independently of APOE polymorphisms. Some recent investigations also suggest that cholinergic abnormalities, as measured by reductions in the neocortical activity of the cholinergic marker enzymes, ChAT and AchE, may not be an early pathophysiological event in AD (Davis et al, 1999; Tiraboschi et al, 2000). Additionally, a study in individuals with mild cognitive impairment actually found an upregulation of ChAT activity in the hippocampus and frontal cortex of this population (DeKosky et al, 2002). It should be noted that the findings from these studies are derived from post-mortem observations. Estimates of the integrity of the cholinergic system captured in these studies are more likely to reflect a static state of the cholinergic system rather than the range of function presumably necessary for normal cognition.

It is possible that the greater sensitivity to anticholinergic toxicity in cognitively intact individuals with the $\varepsilon 4$ allele reflects abnormalities in cholinergic response to a challenge rather than the effects of altered basal cholinergic activity.
Such abnormalities may well go undetected by the static measures of central cholinergic function typically obtained in post-mortem studies. Bartus and Emerich (1999) reported significant cholinergic abnormalities in rodents, primates, and humans in the absence of any significant reduction in ChAT or AchE activity. Poirier (1994) proposed that the $\varepsilon 4$ allele may contribute to a decrease in acetylcholine synthetic capacity and decreased cholinergic synaptic plasticity even in the absence of any reductions in ChAT activity. He suggested that this could arise from previously described APOE4 isoform-specific reductions in the transport of cholesterol and phospholipids, such as phosphatidylcholine and phosphatidylethanolamine, which can serve as precursors to choline in the synthesis of acetylcholine. In animal experiments, the administration of an antimuscarinic challenge, such as the one employed in the current experiment, has been shown to be accompanied by compensatory increases in acetycholine release in various brain regions including the hippocampus (Michikawa et al, 2000; Wood and Cheney, 1979). Thus, reductions in Ach synthetic capacity associated with the $\varepsilon 4$ allele, if confirmed, may reduce the efficiency of the central cholinergic system in overcoming a muscarinic blockade and thereby contribute to our observations. Although at this point the nature of the interaction between the cholinergic system and the $\varepsilon 4$ allele that increases cognitive toxicity is unclear, the present results suggest that the process is dynamic.

In summary, the present results, which need to be confirmed in a larger sample, suggest that the APOE- $\varepsilon 4$ allele is associated with increased sensitivity to anticholinergic treatment-induced memory deficits and a slower recovery from these impairments. Since this particular form of the APOE gene is carried by a significant number of individuals, and treatments with central anticholinergic effects are widely prescribed in the elderly, these preliminary findings, if confirmed, could have important public health implications. From the neuroscience perspective, these findings also suggest the most sensitive indices of cognitive toxicity that may be observed by examining a broader time frame of treatment response than is typically studied.

\section{ACKNOWLEDGEMENTS}

We thank Dr B Imbimbo for valuable comments on earlier versions of this manuscript, $\mathrm{Mr}$ Tom B Cooper and the Analytical Psychopharmacology Laboratory at the Nathan Kline Institute for determination of trihexyphenidyl levels, and $\mathrm{Mr}$ Lawrence Jacobson at the Rockland Psychiatric Center Pharmacy for preparation of study capsules.

\section{REFERENCES}

Agostini JV, Leo-Summers LS, Inouye SK (2001). Cognitive and other adverse effects of diphenhydramine use in hospitalized older patients. Arch Intern Med 161: 2091-2097.

Alberts MJ, Graffagnino C, McClenny C, DeLong D, Strittmatter W, Saunders AM et al (1995). ApoE genotype and survival from intracerebral haemorrhage. Lancet 346: 575.

Allen SJ, MacGowan SH, Tyler S, Wilcock GK, Robertson AGS, Holden PH et al (1997). Reduced cholinergic function in normal 
and Alzheimer's disease brain is associated with apolipoprotein 84 genotype. Neurosci Lett 239: 33-36.

Arndt S, Cizadlo T, O'Leary D, Gold S, Andreasen NC (1996). Normalizing counts and cerebral blood flow intensity in functional imaging studies of the human brain. Neuroimage 3(Part 1): 175-184.

Arendt T, Schindler C, Bruckner MK, Eschrich K, Bigl V, Zedlick D et al (1997). Plastic neuronal remodeling is impaired in patients with Alzheimer's disease carrying apolipoprotein E4 allele. J Neurosci 17: 516-529.

Bartus RT, Emerich DF (1999). Cholinergic markers in Alzheimer disease. JAMA 282: 2208-2209.

Bronfman FC, Tesseur I, Hofker MH, Havekens LM, Van Leuven F (2000). No evidence for cholinergic problems in apolipoprotein E knockout and apolipoprotein $\varepsilon 4$ transgenic mice. Neuroscience 97: 411-417.

Buschke H (1973). Selective reminding for analysis of memory and learning. J Verb Learn Verb Behav 12: 543-550.

Buschke H (1974). Retrieval in human learning. Trans NY Acad Sci 36: 721-729.

Corey-Bloom J, Tiraboschi P, Hansen LA, Alford M, Schoos B, Sabbagh MN et al (2000). E4 allele dosage does not predict cholinergic activity or synapse loss in Alzheimer's disease. Neurology 54: 403-406.

Davis KL, Mohs RC, Marin D, Purohit DP, Perl DP, Lantz M et al (1999). Cholinergic markers in elderly patients with early signs of Alzheimer disease. JAMA 281: 1401-1406.

DeKosky ST, Ikonomovic MD, Styren SD, Beckett L, Wisniewski S, Bennett DA et al (2002). Upregulation of choline acetyltransferase activity in hippocampus and frontal cortex of elderly participants with mild cognitive impairment. Ann Neurol 51: 145-155.

Farlow MR, Cyrus PA, Nadel A, Lahiri DK, Brashear A, Gulanski B (1999). Metrifonate treatment of AD: influence of APOE genotype. Neurology 53: 2010-2016.

Flicker C, Ferris SH, Serby M (1992). Hypersensitivity to scopolamine in the elderly. Psychopharmacology 107: 437-441.

Friedman G, Froom P, Sazbon L, Grinblatt I, Shochina M, Tsenter J et al (1999). Apolipoprotein E-epsilon4 genotype predicts a poor outcome in survivors of traumatic brain injury. Neurology 52: 244-248.

Guthrie SK, Manzey L, Scott D, Giordani B, Tandon R (2000). Comparison of central and peripheral pharmacologic effects of biperiden and trihexyphenidyl in human volunteers. J Clin Psychopharmacol 20: 77-83.

Hixson JE, Vernier DT (1990). Restriction isotyping of human apolipoprotein $\mathrm{E}$ by gene amplification and cleavage with HhaI. J Lipid Res 31: 545-548.

Mayeux R, Ottman R, Maestre G, Ngai C, Tang MX, Ginsberg H et al (1996). Synergistic effects of traumatic head injury and apolipoprotein-epsilon4 in patients with Alzheimer's disease. Neurology 46: 889-891.

McGeer PL, McGeer EG, Suzuki J, Dolman CE, Nagai T (1984). Aging, Alzheimer's disease, and the cholinergic system of the basal forebrain. Neurology 34: 741-745.

Michikawa M, Fan QW, Isobe I, Yanagisawa K (2000). Apolipoprotein $\mathrm{E}$ exhibits isoform-specific promotion of lipid efflux from astrocytes and neurons in culture. J Neurochem 74: 1008-1016.

Molchan SE, Martinez RA, Hill JL, Weingartner HJ, Thompson K, Vitiello B et al (1992). Increased cognitive sensitivity to scopolamine with age and a perspective on the scopolamine model. Brain Res Brain Res Rev 17: 215-226.

Nakra BR, Margolis RB, Gfeller JD, Grossberg GT, Sata LS (1992). The effect of a single low dose of trihexyphenidyl on memory functioning in the healthy elderly. Int Psychogeriatr 4: 207-214.

Poirier J (1994). Apolipoprotein E in animal models of CNS injury and in Alzheimer's disease. Trend Neurosci 17: 525-530.

Poirier J, Delisle MC, Quirion R, Aubert I, Farlow M, Lahiri D et al (1995). Apolipoprotein E4 allele as a predictor of cholinergic deficits and treatment outcome in Alzheimer's disease. Proc Natl Acad Sci USA 92: 12260-12264.

Pomara N, Tun H, DaSilva D, Hernando R, Deptula D, Greenblatt DJ (1998). The acute and chronic performance effects of alprazolam and lorazepam in the elderly: relationship to duration of treatment and self-rated sedation. Psychopharmacol Bull 134: 139-153.

Raskind MA, Peskind ER, Wessel T, Yuan W (2000). Calantamine in $\mathrm{AD}$ : a 6-month randomized, placebo-controlled trial with a 6month extension. The Galantamine USA-1 Study Group. Neurology 54: 2261-2268.

Ray PG, Meador KJ, Loring DW, Zamrini EW, Yang XH, Buccafusco JJ (1992). Central anticholinergic hypersensitivity in aging. J Geriatr Psychiatry Neurol 5: 72-77.

Saunders AM, Strittmatter WJ, Schmechel D, St George-Hyslop PH, Pericak-Vance MA, Joo SH et al (1993). Association of apolipoprotein E allele epsilon4 with late-onset familial and sporadic Alzheimer's disease. Neurology 43: 1467-1472.

Soininen HS, Kosunen O, Helisalmi S, Mannermaa A, Paljarvi L, Talasniemi S et al (1995). A severe loss of choline acetyltransferase in the frontal cortex of Alzheimer patients carrying apolipoprotein E4 allele. Neurosci Lett 187: 79-82.

Sorbi S, Nacmias B, Piacentini S, Repice A, Latorraca S, Forleo P et al (1995). ApoE as a prognostic factor for post-traumatic coma. Nat Med 1: 852.

Sunderland T, Tariot PN, Cohen RM, Weingartner H, Mueller III EA, Murphy DL (1987). Anticholinergic sensitivity in patients with dementia of the Alzheimer type and age-matched controls. A dose-response study. Arch Gen Psychiatry 44: 418-426.

Svensson AL, Warpman U, Lindahl EH, Bogdanovic N, Lannfelt L, Nordberg A (1997). Nicotinic receptors, muscarinic receptors and choline acetyltransferase activity in the temporal cortex of Alzheimer patients with differing apolipoprotein E genotypes. Neurosci Lett 232: 37-40.

Tariot PN, Patel SV, Cox C, Henderson RE (1996). Age-related decline in central cholinergic function demonstrated with scopolamine. Psychopharmacology (Berl) 125: 50-56.

Tiffin J (1968). Purdue Pegboard Examiner's Manual. Science Research Associates: Chicago.

Tiraboschi P, Hansen LA, Alford M, Masliah E, Thal LJ, CoreyBloom J (2000). The decline in synapses and cholinergic activity is asynchronous in Alzheimer's disease. Neurology 55: 1278-1283.

Whitehouse PJ, Price DL, Struble RG, Clark AW, Coyle JT, Delon MR (1982). Alzheimer's disease and senile dementia: loss of neurons in the basal forebrain. Science 215: 1237-1239.

Wood PL, Cheney DL (1979). The effects of muscarinic receptor blockers on the turnover rate of acetylcholine in various regions of the rat brain. Can J Physiol Pharmacol 57: 404-411.

Zemishlany Z, Thorne AE (1991). Anticholinergic challenge and cognitive functions: a comparison between young and elderly normal participants. Isr J Psychiatry Relat Sci 28: 32-41. 